\title{
Peripheral Nerve Injury Leads to Working Memory Deficits and Dysfunction of the Hippocampus by Upregulation of TNF- $\alpha$ in Rodents
}

\author{
Wen-Jie Ren ${ }^{1,5}$, Yong Liu',5, Li-Jun Zhou', Wei Li', Yi Zhong', Rui-Ping Pang', Wen-Jun Xin', Xu-Hong Wei', \\ Jun Wang', He-Quan Zhu', Chang-You Wu ${ }^{3}$, Zhi-Hai Qin ${ }^{4}$, Guosong Liu*,2 and Xian-Guo Liu*,' \\ 'Pain Research Center, Department of Physiology, Zhongshan School of Medicine, Sun Yat-sen University, Guangzhou, China; ${ }^{2}$ Center for \\ Learning and Memory, School of Medicine, Tsinghua University, Beijing, China; ${ }^{3}$ Department of immunology, Zhongshan School of Medicine, \\ Sun Yat-sen University, Guangzhou, China and ${ }^{4}$ National Key Laboratory of Biomolecules, CAS-UT Joint Lab of Structural Virology and \\ Immunology, Institute of Biophysics, Chinese Academy of Sciences, Beijing, China
}

\begin{abstract}
Patients with chronic pain usually suffer from working memory deficits, which may decrease their intellectual ability significantly. Despite intensive clinical studies, the mechanism underlying this form of memory impairment remains elusive. In this study, we investigated this issue in the spared nerve injury (SNI) model of neuropathic pain, a most common form of chronic pain. We found that SNI impaired working memory and short-term memory in rats and mice. To explore the potential mechanisms, we studied synaptic transmission/ plasticity in hippocampus, a brain region critically involved in memory function. We found that frequency facilitation, a presynaptic form of short-term plasticity, and long-term potentiation at CA3-CAI synapses were impaired after SNI. Structurally, density of presynaptic boutons in hippocampal CAI synapses was reduced significantly. At the molecular level, we found that tumor necrosis factor- $\alpha$ (TNF- $\alpha$ ) increased in cerebrospinal fluid, in hippocampal tissue and in plasma after SNI. Intracerebroventricular or intrahippocampal injection of recombinant rat TNF mimicked the effects of SNI in naive rats, whereas inhibition of TNF- $\alpha$ or genetic deletion of TNF receptor I prevented both memory deficits and synaptic dysfunction induced by SNI. As TNF- $\alpha$ is critical for development of neuropathic pain, we suggested that the over-production of TNF- $\alpha$ following peripheral nerve injury might lead to neuropathic pain and memory deficits, simultaneously.

Neuropsychopharmacology (20 I I) 36, 979-992; doi: I0.1038/npp.2010.236; published online 2 February 20I I
\end{abstract}

Keywords: spared nerve injury; chronic neuropathic pain; working memory; long-term potentiation; presynaptic boutons; tumor necrosis factor- $\alpha$

\section{INTRODUCTION}

Compelling clinical evidence has shown that chronic pain patients (without traumatic brain injury or neurological disorder) usually suffer from memory deficits (Hart et al, 2000; Legrain et al, 2009). Around two-third of patients with chronic pain exhibit disruption of working memory (Dick and Rashiq, 2007). Psychologically, working memory is associated with ability of people to remember and process

*Correspondence: Dr X-G Liu, Pain Research Center, Department of Physiology, Zhongshan School of Medicine, Sun Yat-sen University, Guangzhou 510080, China, Tel: +86-20-87331956, Fax: +86-2087331956, E-mail: liuxg@mail.sysu.edu.cn or Dr G Liu, Center for Learning and Memory, School of Medicine, Tsinghua University, Beijing 100084, China, Tel: + 86-10-62795299, Fax: + 86-10-62784790, E-mail: liu.guosong@gmail.com

${ }^{5}$ Those authors contributed equally to this work

Received 6 June 2010; revised 14 November 2010; accepted

17 November 2010 short-term information for making decisions or solving problems. It has been shown that intact working memory is critical for achievements of an individual in modern life (Alloway et al, 2009).

Although numerous clinical studies have been carried out to elucidate why chronic pain patients have memory deficits, the results are controversial. Some studies suggest that memory impairment may be associated with intensity of pain (see Hart et al, 2000 for a review). However, other studies show that acute pain in health individual is not always associated with cognitive deficit (Etherton et al, 2006) and that the relief of pain in chronic pain patients with opioids fails to improve their cognitive function (Dick and Rashiq, 2007). Thus, the mechanisms underlying the memory deficits in chronic pain patients remain elusive.

To explain why chronic pain patients have memory deficits, two attractive but different theories have been raised. Eccleston (1995) has suggested that attention, which is closely relevant to working memory (Awh et al, 2006), is a 
finite and unitary resource and pain-related sensory inputs compete for the limited attention resources, thereby affecting the working memory process that involves the processing and integrating of other information. Hence, disruption of attention by pain may lead to memory deficits. Alternatively, Hart et al (2000) propose that the chemical substances produced in chronic pain conditions may influence function of neural circuitries, leading to the impairment of attention and memory. Therefore, memory impairment may be not resulted from pain, but rather from unknown sources.

The most common form of chronic pain is neuropathic pain (Toth et al, 2009), which is initiated or caused by a primary lesion or dysfunction in the nervous system (International Association for the Study of Pain, 1986). It has been repeatedly demonstrated that the upregulation of proinflammatory cytokines following nerve injury have a key role in the development of neuropathic pain (George et al, 2004; Noguchi et al, 2004; Shamash et al, 2002; Yamanaka et al, 2004). Tumor necrosis factor- $\alpha$ (TNF- $\alpha$ ), a key pro-inflammatory cytokine, increased substantially in dorsal root ganglia (DRG), spinal dorsal horn, and hippocampus following peripheral nerve injury (Ignatowski et al, 1999; Spengler et al, 2007; Xu et al, 2006) and inhibition of TNF- $\alpha$ synthesis (George et al, 2000; Ribeiro et al, 2000; Xu et al, 2006) or antagonism of TNF receptor 1 (TNFR1; Schafers et al, 2001; Sommer et al, 2001) attenuates the behavioral signs of neuropathic pain.

In this study, we explored the memory function in the spared nerve injury (SNI) model of neuropathic pain (Decosterd and Woolf, 2000) and found that indeed, working memory or short-term memory was impaired severally after SNI. As synaptic density and plasticity in hippocampus are critical for memory formation (BruelJungerman et al, 2007; Gould and Leuner, 2010; Leuner and Shors, 2004), we studied the synaptic transmission and plasticity in hippocampus in animal with SNI and found that both short-term and long-term synaptic plasticity was impaired. Finally, we showed that the increase in TNF- $\alpha$, which induces neuropathic pain, led to memory deficits following peripheral nerve injury.

\section{MATERIALS AND METHODS}

\section{Animals}

Adult male Sprague-Dawley rats (220-260 g), adult male C57 mice (22-27 g) from Institute of Experimental Animal of Sun Yat-sen University and adult male TNFR1-knockout (KO) mice weighing 22-27 $\mathrm{g}$ from the Jackson's laboratory were used. The animals were housed in separated cages with access to food and water ad libitum. The room was kept at $23 \pm 1{ }^{\circ} \mathrm{C}$ and $50-60 \%$ humidity, under a light cycle $(0600$ to 1800 hours). All experimental procedures were approved by the Local Animal Care Committee.

\section{Spared Nerve Injury}

The SNI procedure was carried out following the procedures described by Decosterd and Woolf (2000). Under anesthesia with chloral hydrate $(0.4 \mathrm{~g} / \mathrm{kg}$, i.p.), an incision through skin on the lateral surface of the thigh was made, and the biceps femoris muscle was dissected bluntly to expose the left sciatic nerve and its three terminal branches. The common peroneal and the tibial nerves were tightly ligated with 5-0 silk and transected distal to the ligation, removing a 2-4 mm length of each nerve. Great care was taken to avoid any contact with or stretching of the intact sural nerve. The wound was closed in two layers.

\section{Measurement of Mechanical Allodynia}

Mechanical sensitivity was assessed using von Frey hairs with the up-down method as described previously (Chaplan et al, 1994). Briefly, the animals were placed under separate transparent Plexiglas chambers positioned on a wire mesh floor. Five minutes were allowed for habituation. Each stimulus consisted of a 2-3 s application of the von Frey hair to the lateral surface of the foot with a 5 min interval between stimuli. Quick withdrawal or licking of the paw in response to the stimulus was considered a positive response. The paw withdrawal threshold was monitored before and after SNI, and before electrophysiological recordings or before the animal was killed for immunohistochemistry or TNF- $\alpha$ bioassay.

\section{Eight-Arm Radial Maze Test}

To evaluate the working memory and reference memory in animals with SNI and sham operation (10-20 day group and 30-40 day group), the eight-arm radial maze test was performed following the method described by Zou et al (1998). The animals were singly housed and kept on a restricted diet and body weight was maintained at $85 \%$ of their free-feeding weight, with water being available ad libitum The radial maze consisted of a central octagonal platform $(26 \mathrm{~cm}$ in diameter), from which eight arms $(67 \mathrm{~cm}$ long, $20 \mathrm{~cm}$ deep, $10 \mathrm{~cm}$ wide) radiated. At the end of each arm there was a $3 \mathrm{~mm}$ deep food cup ( $3 \mathrm{~mm}$ in diameter) that was invisible from the center of the maze. The experimental room was brightly lit and decorated with conspicuous extra-maze cues. The cues remained constant throughout the experiment.

The animals were first habituated to eat food pellets placed in all arms of the radial maze. Once all the animals were running freely through the maze and readily consuming the pellet rewards at the first entry of each arm, memory testing began. During the tests, only four of eight arms were baited with one $100 \mathrm{mg}$ (for rat) or $15 \mathrm{mg}$ (for mouse) in hidden food pellet. The four baited arms were allocated such that two of these arms were adjacent, and the other arms were $90^{\circ}$ apart from these arms (eg, arms 1, 3, 6, and 8 ) and that were kept constant throughout the 10 days of testing for each animal. The trial commenced with placement of the animal on the central platform and was deemed finished as soon as the food pellets had been consumed or when $10 \mathrm{~min}$ had elapsed, whichever occurred first. At the end of each trial, the maze was cleaned. The number of arm entries was recorded until the trial was finished. The maze was rotated periodically to prevent the animals from using intra-maze cues to solve the task. The locomotion of each animal was monitored during the whole memory test and the data is shown in Supplementary Figure 1. 
Entry into an unbaited arm was scored as a reference memory error. This reflects memory of information, which remains constant across trials and is a measure of long-term memory. Re-entry into a baited arm from which the food pellet had already been consumed within a trial was scored as a working memory error. This mirrors the ability of the animal to retain short-term information for a single trial, ie, to temporarily hold information online, and is a measure of working memory. The animals, which entered less than three arms or more than 20 arms in the first 2 min of the habituation phase, were considered inactive or excessively active and were excluded from the test. The tests were performed in two different cohorts of rats: 11-20 days and 31-40 days after SNI or sham operation.

\section{Electrophysiological Recording of Field Excitatory Postsynaptic Potentials in CA3-CA1 Synapses In Vivo}

Following the procedures described previously (Xu et al, 1997), animals anaesthetized with urethane (1.5 g/kg, i.p.) were placed in a stereotaxic frame. Field excitatory postsynaptic potentials (fEPSPs) were recorded from the stratum radiatum in CA1 following electrical stimulation of the Schaffer collateral-commissural pathway. Electrophysiological criteria (Leung, 1979) were used to determine the optimal electrode placement. The recording electrode was positioned $3.4 \mathrm{~mm}$ in rat $(2.3 \mathrm{~mm}$ in mouse) posterior to bregma, $2.5 \mathrm{~mm}$ in rat $(1.75 \mathrm{~mm}$ in mouse) lateral to midline, and the depth of recording electrode was about $2.2 \mathrm{~mm}$ in rat (1.6 $\mathrm{mm}$ in mouse) from dura. The stimulating electrode was positioned $4.2 \mathrm{~mm}$ in rat $(1.7 \mathrm{~mm}$ in mouse) posterior to bregma and $3.8 \mathrm{~mm}$ (1.6 $\mathrm{mm}$ in mouse) lateral to midline, and about $4.7 \mathrm{~mm}$ in depth in rat $(1.8 \mathrm{~mm}$ in mouse) from dura. The positions of recoding electrode and stimulation electrode in a representative experiment in rat are shown in Supplementary Figure $2 \mathrm{c}-\mathrm{d}$. A single square pulse of voltage at low frequency $(0.066 \mathrm{~Hz}, 0.2 \mathrm{~ms}$ duration) was used to evoke fEPSPs and the intensity of the test stimulus was adjusted to produce $50-55 \%$ of maximum response. High-frequency stimulation (HFS, $100 \mathrm{~Hz}, 50$ pulses, four trains at $15 \mathrm{~s}$ interval) protocol was used to induce long-term potentiation (LTP). The intensity of HFS was raised to evoke $75 \%$ of maximum fEPSPs amplitude. The amplitudes of fEPSPs were determined on-line by LTP program (http://www.ltp-program.com). In each experiment, the responses to twenty consecutive test stimuli were averaged. The mean amplitudes of responses before HFS served as baseline. The recordings were made before and in different time periods after SNI or sham operation (Figure 2).

To measure the frequency facilitation in CA1 synapses, a presynaptic form of short-term plasticity (Sun et al, 2005), 100 conditioning stimuli at 2,4 , and $8 \mathrm{~Hz}$ were in turn delivered in the same animal at $20 \mathrm{~min}$ intervals. Stable baseline was recorded before conditioning stimuli. The intensity of conditioning stimuli was identical to test stimuli. The frequency facilitation was recorded at 20 days after SNI and sham operations.

\section{The Quantification of Presynaptic Terminal Puncta and TNF- $\alpha$}

The detection of presynaptic terminal puncta with synaptophysin antibody in brain sections was performed as following. The image was collected with an Olympus IX70 confocal microscope using a $\times 60$ water lens; water lens $(\mathrm{N} / \mathrm{A}=1.2)$ at zoom $\times 3$, generating an image with $78.6 \times 78.6 \mu \mathrm{m}$ dimension. Serial $\mathrm{z}$-sectioning was performed (thickness of $0.9 \mu \mathrm{m}$ ) and the best three z-sections (with highest number of puncta) were collected and merged into a single image. The number of puncta in the CA1 region was estimated from the obtained images using Image-Pro-Plus software (Media Cybernetics). Background levels were equalized and special filters to separate fluorescent puncta were applied. Settings, for each image, were adjusted to maximize the number of detected fluorescent puncta. Mean puncta number per $1000 \mu \mathrm{m}^{2}$ was calculated. The difference in presynaptic terminal puncta density between each group should still be reliable, as all images were processed under the same conditions.

The sections stained with TNF- $\alpha$ antibody were examined with a Leica DFC350 FX (Leica Camera, Germany) fluorescence microscope and images were captured with a CCD spot camera. To quantify TNF- $\alpha$ immunofluorescence staining, the area of TNF- $\alpha$-IR per section was measured in the hippocampus CA1 and CA 3 areas using a computerized image analysis system (LAICA Qwin). A density threshold was set above background level to identify positively stained structures, and then the percentage of TNF- $\alpha$-IR area in the whole tissue area was calculated. The brain sections were coded until the completion of data analysis.

\section{Statistics}

The data from the radial eight-arm maze, LTP, and frequency facilitation between groups were analyzed with repeated measures two-way ANOVA, and post hoc test were used for detailed statistical analysis, as appropriate. For paw withdrawal threshold, non-parametric tests were used. The data between testing days within group were analyzed with Friedman ANOVA for repeated measurements, followed by Wilcoxon's matched pairs test when appropriate, and the data between groups on a given testing day were analyzed with the Mann-Whitney $U$-test. The results of immunohistochemistry and the novel object recognition test were analyzed with two-tailed unpaired Student's $t$-tests. The data of TNF- $\alpha$ bioassay were analyzed using one-way ANOVA followed by individual post hoc comparisons (Tukey post hoc test), whereas the data of TNF- $\alpha$ bioassay between two groups was compared with two-tailed unpaired Student's $t$-tests. The correlation of two parameters in one group was analyzed with the Pearson's test. All data are expressed as means \pm SEM. Statistical tests were carried out with SPSS 16.0 (SPSS, Somers, NY, USA). A $P$-value of $<0.05$ was considered significant.

\section{RESULTS}

\section{Working Memory and Short-Term Memory are Impaired in Rats Following SNI}

To test whether peripheral nerve injury, which often induces neuropathic pain, may impair memory function in adult rats, radial eight-arm maze tests were performed at 11-20 days after SNI and sham operation. The paw withdrawal thresholds were significantly decreased in the 

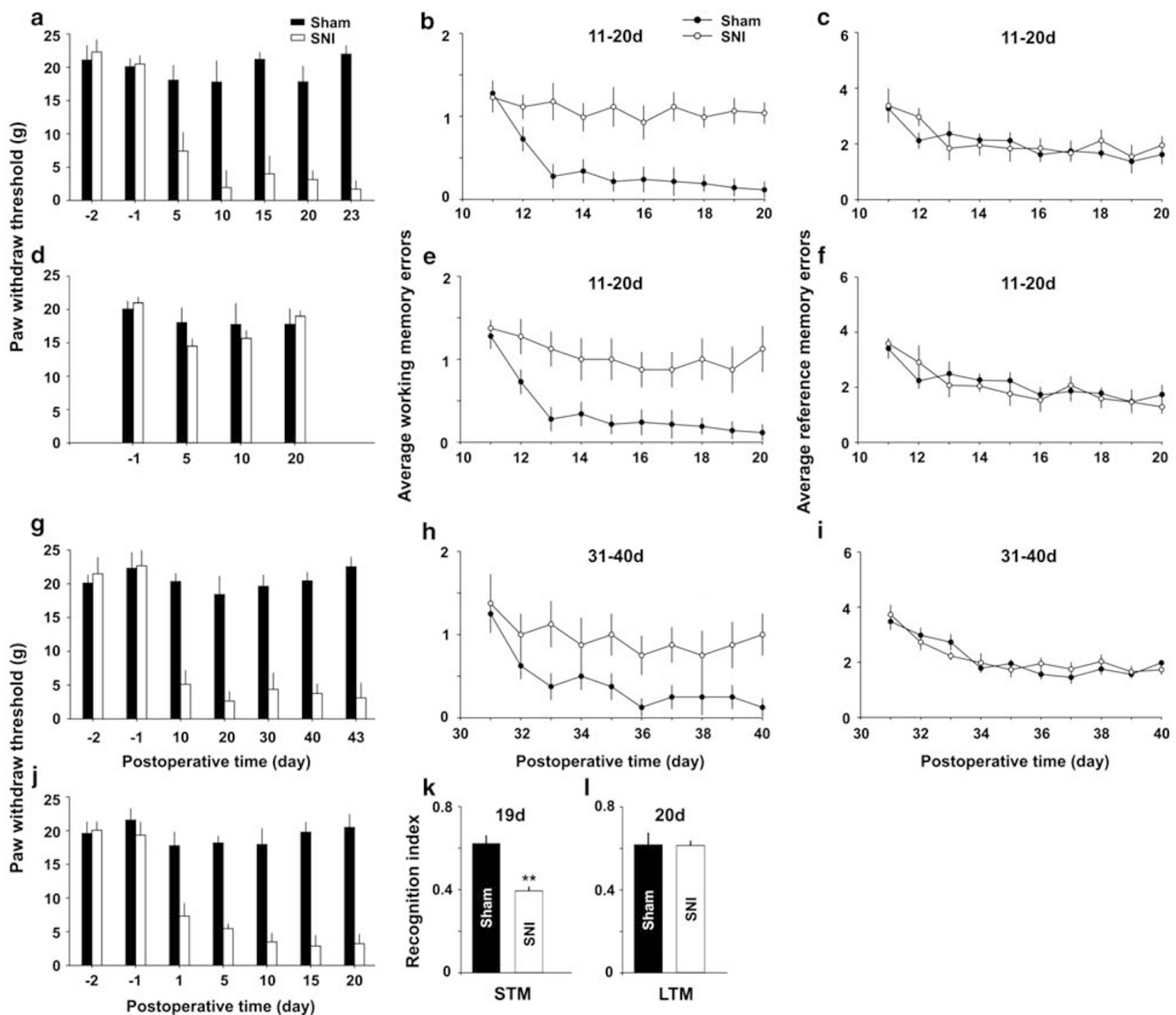

Figure I SNI impairs spatial working memory and short-term memory (STM), but not spatial reference memory or long-term memory (LTM) in rats. (a) The mechanical allodynia was verified by lasting decrease in paw withdrawal thresholds on ipsilateral side in SNI group, compared with those in sham group ( $n=15$ in SNI group and $n=20$ in sham group). (b and c) In the same rats working memory and reference memory were evaluated with radial eightarm maze at I I-20 days after operation. ( $\mathrm{d}-\mathrm{f}$ ) In the five rats that did not exhibit significant decrease in paw withdrawal thresholds following SNI, working memory errors but not reference memory errors were also significantly higher, compared with sham group ( $n=20$ in sham group). (g-i) Paw withdrawal thresholds, working memory and reference memory in the rats at $31-40$ days after $\mathrm{SNI}$ and sham operation are shown ( $n=10$ in each group). (j-I) Paw withdrawal thresholds were tested in SNI and sham groups, and the recognition index for STM and for LTM were determined by novel object recognition test at 19 days and at 20 days after operation. $* * *<0.01$ compared with sham groups $(n=8$ in each group). Data are presented as means \pm SEM.

SNI group (Figure 1a, $n=15, \mathrm{~F}_{(6,98)}=53.95, \quad P<0.01$ compared with pre-operation, Friedman ANOVA), but not in the sham group (Figure 1a and $\mathrm{d}, n=20, \mathrm{~F}_{(6,133)}=2.44$, $P>0.05$ vs preoperative baseline, Friedman ANOVA). The average working memory errors in the SNI rats with mechanical allodynia was significantly higher than those in sham group from the third to tenth test day (Figure $1 \mathrm{~b}$, $\mathrm{F}_{(1,33)}=24.46, P<0.05, n=15$ in SNI group and $n=20$ in sham group, two-way ANOVA followed by post hoc test), whereas no difference in the average reference memory errors was detected between SNI group and sham group (Figure $1 \mathrm{c}, \mathrm{F}_{(1,33)}=1.97, P>0.05$, two-way ANOVA).

To investigate the causal relation between mechanical allodynia and memory deficits, we tested memory function in another five rats that did not exhibit the decrease in paw withdrawal thresholds following SNI (Figure 1d, $n=5$, $\mathrm{F}_{(6,28)}=0.64, P>0.05$ compared with pre-operation, Friedman ANOVA). Surprisingly, working memory errors in these rats were also higher, compared with sham group (Figure 1e, $\mathrm{F}_{(1,23)}=15.24, P<0.05, n=5$ in SNI group, and $n=20$ in sham group, two-way ANOVA), whereas the reference memory was not different from sham group (Figure 1f, $P>0.05, \mathrm{~F}_{(1,23)}=1.67$, two-way ANOVA). The results suggest that mechanical allodynia might be not directly relevant to the memory deficits produced by SNI.

In other 20 rats, the memory function was evaluated at 31-40 days after operation. Paw withdrawal thresholds decreased in SNI group (Figure 1g, $\mathrm{F}_{(6,63)}=43.85, P<0.01$ 
compared with pre-operation, $n=10$ in each group, Friedman ANOVA). We found again that the average working memory errors were significantly higher in SNI group than in sham group from the third test day (Figure $1 \mathrm{~h}, \mathrm{~F}_{(1,18)}=12.04, P<0.05, n=10$ in each group, two-way ANOVA followed by post hoc test), and there was no difference in the average reference memory errors between the two groups (Figure $1 \mathrm{i}, \mathrm{F}_{(1,18)}=1.07, P>0.05$, two-way ANOVA).

To investigate further the effect of SNI on memory function, the short-term memory and long-term memory were individually evaluated using the novel object recognition test (NORT) on day 19 and day 20 after operation (see Supplementary Methods). The recognition index for shortterm memory ( $10 \mathrm{~min}$ rotation) but not that for long-term memory ( $24 \mathrm{~h}$ rotation) in the same cohorts of rats was significantly lower in SNI group than in sham group (Figure $1 \mathrm{k}$ and $1, P<0.01, n=8$ in each group, two-tailed unpaired Student's $t$-test).

No significant difference in locomotion activity between SNI and sham groups was detected (Supplementary Figure $1 \mathrm{a}-\mathrm{c}$ and Supplementary Figure $1 \mathrm{j}$ ).

\section{SNI Leads to a Delayed Inhibition of LTP in Bilateral Hippocampus}

To explore the synaptic mechanisms underlying the memory impairment produced by peripheral nerve injury, we recorded LTP in hippocampus in vivo at different time points after SNI and sham-operation. We focused in the CA3-CA1 synapses, because both CA1 and CA3 are important for working memory and novelty detection (Kesner, 2007; Vago and Kesner, 2008).

As it has been proposed that pain may lead to memory deficits (Eccleston, 1995), to test whether the intensive nociceptive inputs produced by peripheral nerve injury may directly affect synaptic transmission and plasticity in hippocampus, fEPSPs were recorded in vivo in either ipsilateral or contralateral hippocampus before and after SNI performed on left side. We found that SNI did not affect the amplitudes of fEPSPs at ipsilateral CA1 (Figure 2a, $\mathrm{F}_{(2,12)}=0.918, P>0.05$ vs preoperative baseline, $n=5$, oneway ANOVA) and the magnitude of LTP induced by HFS at $1 \mathrm{~h}$ after SNI was not different from that in sham group (Figure $2 \mathrm{a}, \mathrm{F}_{(1,8)}=1.266, P>0.05, n=5$ in each group, twoway ANOVA). SNI also did not affect amplitudes of fEPSPs recorded in contralateral CA1 (Supplementary Figure 2a, $\mathrm{F}_{(2,12)}=1.561, P>0.05$ vs preoperative baseline, $n=5$, oneway ANOVA) and LTP induction (Supplementary Figure 2a, $\mathrm{F}_{(1,8)}=6.715, P>0.05$, compared with sham group, $n=5$ in each group, two-way ANOVA). Whereas, in 18-20 h after SNI group, the potentiation by HFS returned to baseline within $1 \mathrm{~h}$ (Figure $2 \mathrm{~b}, \mathrm{~F}_{(1,10)}=29.81, P<0.05$ compared with sham group, $n=6$ in each group, two-way ANOVA followed by post hoc test), indicating late-phase LTP was abolished. Furthermore, at 6-10 days after SNI, the potentiation by HFS persisted for $<30 \mathrm{~min}$ (Figure $2 \mathrm{c}, n=6, \mathrm{~F}_{(1,10)}=57.60$, $P>0.05$ compared with sham group, two-way ANOVA followed by post hoc test), suggesting LTP was completely blocked and only short-term potentiation remained.

To determine the relationship between LTP inhibition and memory impairment, we tried to record LTP in the rats that were used for radial maze memory tests (shown in Figure $1 \mathrm{a}-\mathrm{c}$ and Figure $1 \mathrm{~g}-\mathrm{i}$ ), and found that HFS failed to induce LTP in 23-25 day and 43-45 day SNI groups (Figure $2 \mathrm{~d}$ and e, $n=10-15$ in each group). We also evaluated the synaptic plasticity in the rats that did not exhibit mechanical allodynia but had working memory deficits (shown in Figure 1d-f), and found that HFS also failed to induce LTP in these animals (Figure $2 \mathrm{f}, n=5$ ). Furthermore,

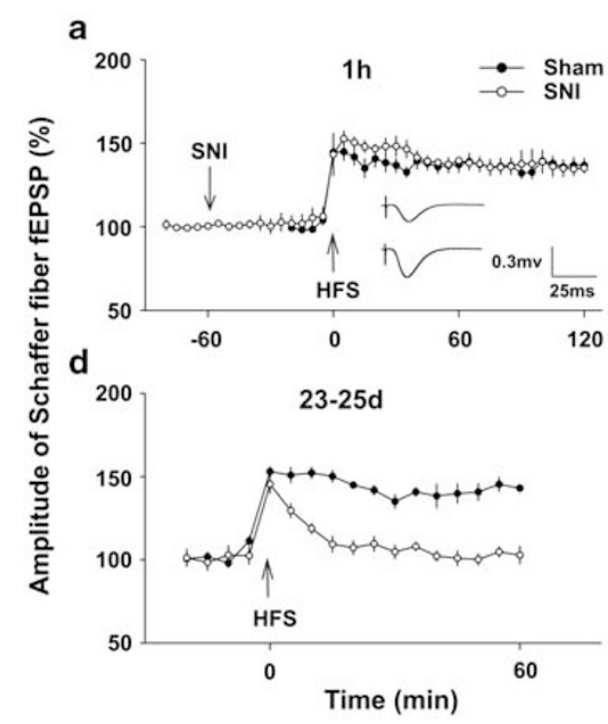

b

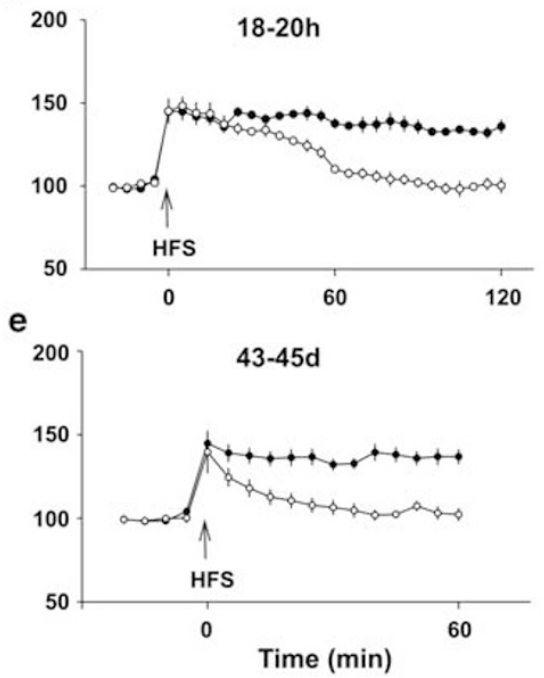

C

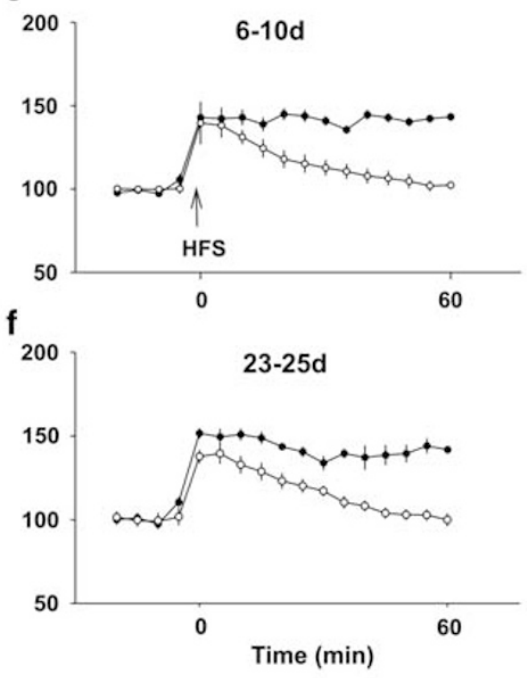

Figure 2 SNI inhibits LTP in CA3-CAI synapses in a time-dependent manner. (a) SNI did not affect the baseline of fEPSPs and LTP induction by HFS $(100 \mathrm{~Hz}, 50$ pulses, four trains with $15 \mathrm{~s}$ intervals), which was delivered at I $\mathrm{h}$ after nerve injury $(n=5$ in each group). Insert: the raw traces of fEPSPs before (top trace) and after (bottom trace) HFS. (b and c) The time courses of potentiation by HFS in I $8-20 \mathrm{~h}$ and $6-10$ day SNI group ( $n=6$ in each group). ( $d$ and e) The recordings were made following behavioral test as illustrated in Figure Ia-c and Figure Ig-i $(n=10-15$ in each group). (f) The recordings were made in rats ( $n=5$ in SNI group and $n=20$ in sham group) that did not exhibit allodynia but had working memory deficits, as shown in Figure I $-f$. Data are presented as means \pm SEM. 
a
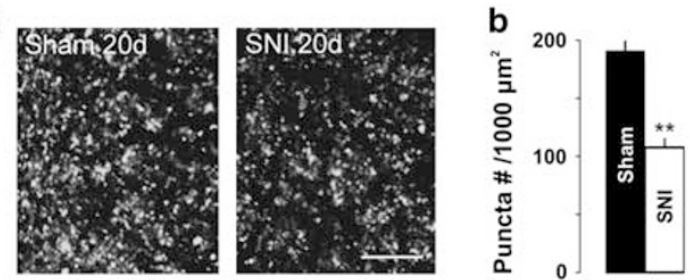

e

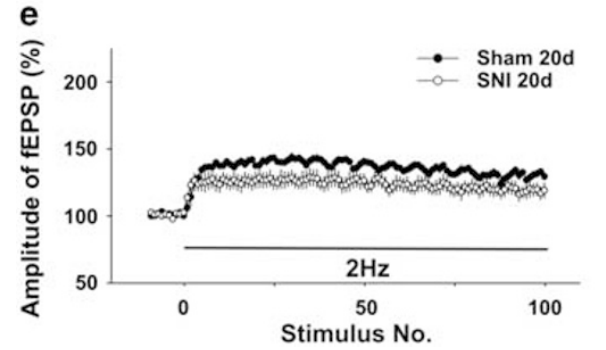

f c

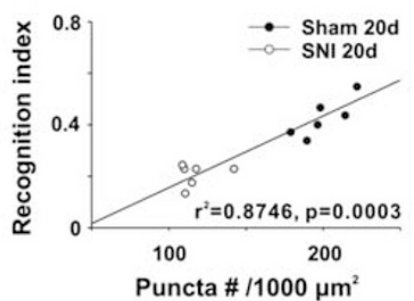

d

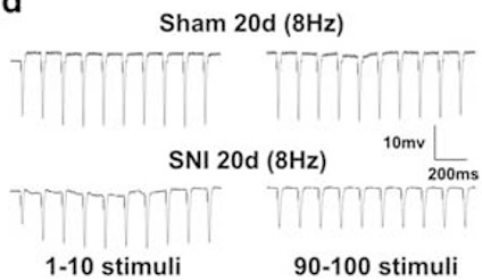

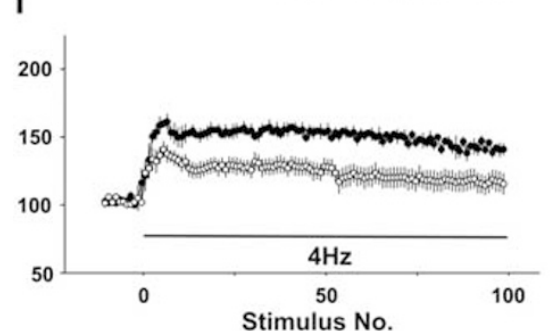

g

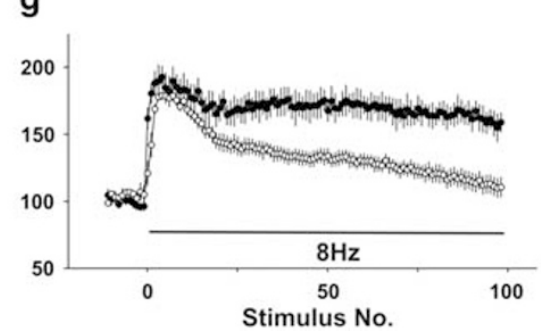

Figure 3 SNI reduces presynaptic terminal puncta density and frequency facilitation in CAI region. (a) The representative images of presynaptic terminal synaptophysin puncta in CAI from a 20-day-SNI rat and a sham-operated rat are shown. Scale bar $=10 \mu m$. (b) The summary data of presynaptic terminal puncta densities in SNI group and sham group ( $n=8$ in each group). (c) The correlation between presynaptic terminal puncta density and the recognition index for short-term memory $\left(r^{2}=0.8746, P=0.0003\right.$ ). (d) Original traces of fEPSPs evoked by $8 \mathrm{~Hz}$ stimuli in a SNI rat and a sham-operated rat. (e-g) The facilitation of fEPSPs produced by 2,4 , and $8 \mathrm{~Hz}$ stimuli in same SNI rats and in sham rats ( $n=5$ in each group) in 20 min intervals. The test stimulation was $0.066 \mathrm{~Hz}$, and the intensity of conditioning stimuli was identical to that of test stimuli. $* * P<0.01$ compared with sham groups and data are presented as means \pm SEM.

HFS was unable to induce LTP in contralateral hippocampus at 20 days after SNI (Supplementary Figure 2b), which was tested in other five rats. In contrast, LTP persisted until to the end of experiments (up to $5 \mathrm{~h}$ ) in all sham-operated groups (Figure 2, $P<0.01$ compared with baseline, one-way ANOVA, $n=5-20$ in each time period). The delayed and bilateral inhibitory effect of SNI on hippocampal LTP suggested that peripheral nerve injury might impair memory function, indirectly.

\section{SNI Reduces Both Presynaptic Boutons and the Frequency Facilitation at CA3-CA1 Synapse}

As the amount of synaptic connections is critical for memory function (Bruel-Jungerman et al, 2007), we compared the number of presynaptic boutons by calculating the density of synaptophysin-positive puncta (a vesicle protein) in stratum radiatum of CA1 between SNI and sham rats, which had been used for novel object recognition test (shown Figure 1j-1). The density of puncta was significantly lower in SNI group than that in sham group (Figure $3 \mathrm{a}$ and $\mathrm{b}$, $P<0.01, n=8$ in each group, two-tailed unpaired Student's $t$-test). Interestingly, we found that the density of puncta was positively correlated with recognition index for shortterm memory in individual rats (Figure $3 c, r^{2}=0.8746$, $P=0.0003$, Pearson test). Thus, the reduction of presynaptic boutons might be a structural basis of the memory impairment produced by SNI.

As the reduction of the synaptophysin in presynaptic terminals may affect presynaptic release during synaptic transmission, we next tested whether the frequency facilitation, which is closely related to presynaptic neurotransmitter release (Sun et al, 2005), might be changed following SNI. The magnitude of facilitation induced by $2 \mathrm{~Hz}$ stimulation in SNI group was not different from that in sham group (Figure $3 e, \mathrm{~F}_{(1,8)}=0.21, P>0.05, n=5$ in each group, two-way ANOVA). However, the facilitation induced by 4 and $8 \mathrm{~Hz}$ were significantly lower in SNI rats than those in sham-operated rats (Figure $3 \mathrm{f}$ and $\mathrm{g}, \mathrm{F}_{(1,8)}=0.33, P<0.05$ and $\mathrm{F}_{(1,8)}=3.48, P<0.01$, respectively, $n=5$ in each group, two-way ANOVA). Furthermore, in SNI group the facilitation induced by 2 and $4 \mathrm{~Hz}$ stimulation persisted during 100 stimuli (Figure $3 e$ and $\mathrm{f}$ ), whereas the facilitation induced by $8 \mathrm{~Hz}$ decreased progressively and returned to baseline at the end of stimulation (Figure $3 \mathrm{~d}$ and $\mathrm{g}$ ). The decrease in frequency facilitation in CA3-CA1 synapses following SNI might contribute to the impairment of working memory.

\section{TNF- $\alpha$ is Increased in Cerebrospinal Fluid, Hippocampus, and Plasma Following SNI}

Previous studies have shown that TNF- $\alpha$ is upregulated in DRG and spinal dorsal horn (Xu et al, 2006) following nerve injury, and that TNF- $\alpha$ at pathological concentration inhibits LTP in hippocampus (Pickering et al, 2005) and impairs cognitive function (Tobinick, 2009). Accordingly, we tested whether TNF- $\alpha$ is increased in CSF, in hippocampal tissue, and in plasma at different time points following SNI (see Supplementary Methods). Indeed, the concentrations of TNF- $\alpha$ in CSF increased significantly at $5 \mathrm{~h}$ following SNI, reaching to peak at $10 \mathrm{~h}$, remaining at high level at 6 days, 20 days after SNI (Figure 4a, $\mathrm{F}_{(5,24)}=64.02, P<0.01$ compared with control $(0 \mathrm{~h}), n=5$ in each group, one-way ANOVA followed by post hoc test). In hippocampal tissue, TNF- $\alpha$ did not change immediately after SNI, but increased at $18 \mathrm{~h}$ after SNI and persisted for at least 40 days (Figure $4 \mathrm{~b}, \mathrm{~F}_{(5,24)}=16.10, P<0.01$ compared with control $(0 \mathrm{~h}), n=5$ in each group, one-way ANOVA followed by post hoc test). We found that the amplitudes of fEPSPs recorded at $30 \mathrm{~min}$ after HFS were negatively 


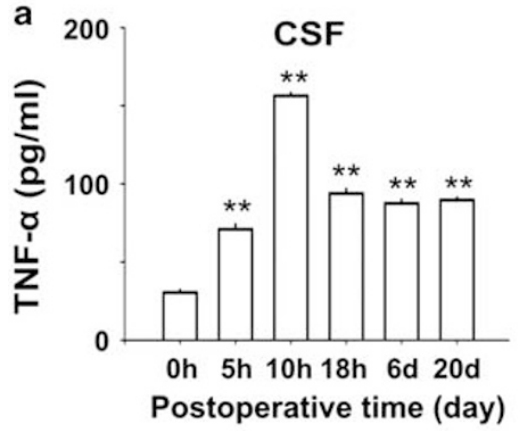

d
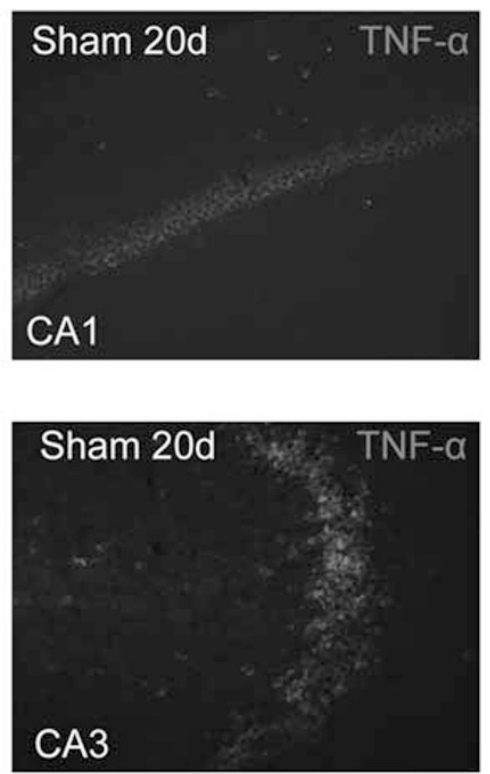
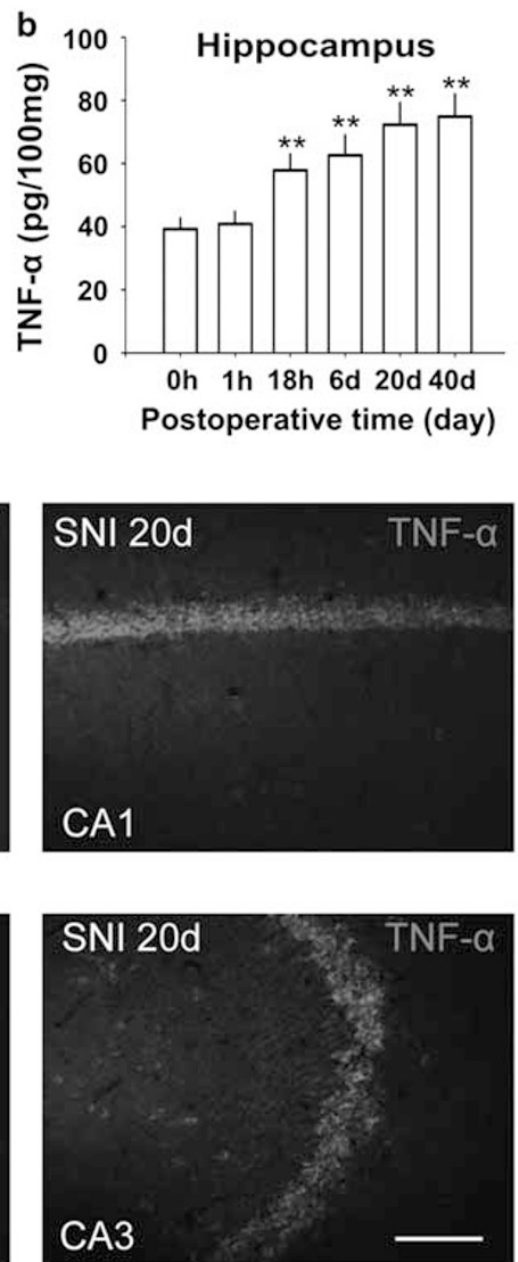

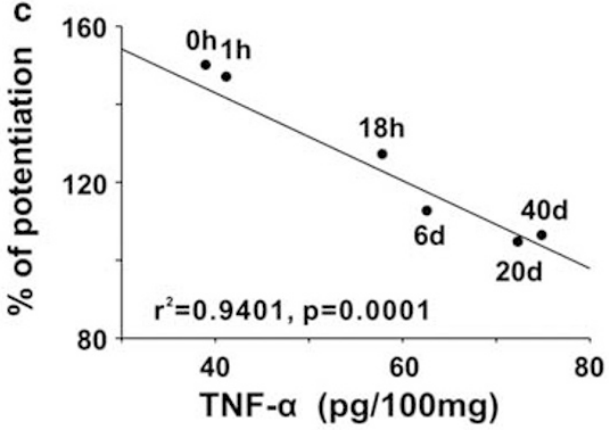

e

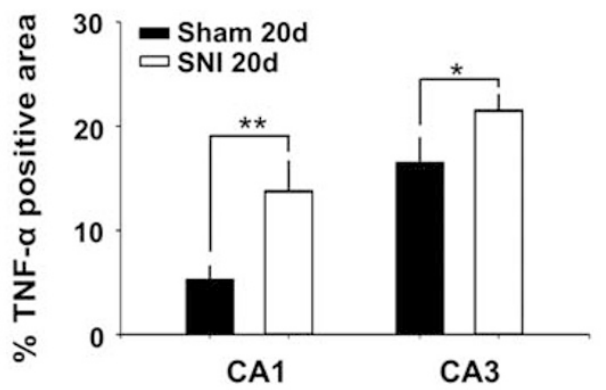

$f$

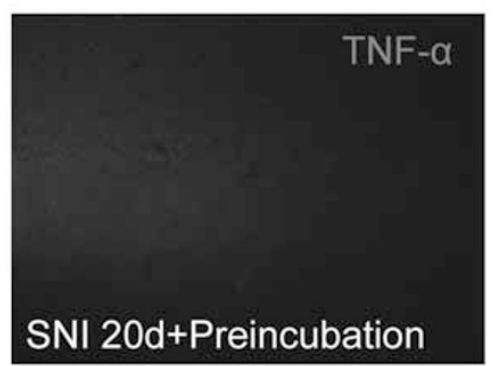

Figure $4 \mathrm{SNI}$ increases TNF- $\alpha$ in cerebrospinal fluid and hippocampal tissue and the concentration of TNF- $\alpha$ in hippocampus is correlated with LTP inhibition. ( $a$ and b) The concentrations of TNF- $\alpha$ in cerebrospinal fluid (CSF) and in hippocampal tissue at different time points following SNI ( $n=5$ at each time point). (c) The correlation analysis between the amplitude of fEPSPs recorded at $30 \mathrm{~min}$ after HFS and the concentrations of TNF- $\alpha$ in hippocampal tissue at different time points following SNI $(n=5-20$ at each time point). $* * *<0.0$ I compared with the time point of $0 \mathrm{~h}$ after SNI. (d) Representative experiments showed the difference in TNF- $\alpha$-IR area in CAI and CA3 between sham operated and SNI rats. (e) The histogram showed the summary data $(n=6)$ of TNF- $\alpha$-IR-positive staining area in CAI and CA3 in sham and SNI groups. (f) Identification of specificity of anti-TNF- $\alpha$ used in this study. The TNF- $\alpha-$ IR was clearly decreased in serial sections by preincubating anti-TNF- $\alpha$ antibody with TNF- $\alpha$. Scale bar $=50 \mu \mathrm{m}$. $* P<0.05$, $* * * P<0.0$ I vs sham groups. Data are presented as means \pm SEM.

correlated with the concentrations of TNF- $\alpha$ in hippocampus (Figure $4 \mathrm{c}, r^{2}=0.9401, P=0.0001$, Pearson test) in SNI rats. The level of TNF- $\alpha$ in plasma also increased significantly at 3 days and at 7 days after SNI, compared with control (Supplementary Figure 3, $\mathrm{F}_{(2,12)}=21.53, P<$ 0.01 compared with control $(0 \mathrm{~h}), n=5$ in each group, one-way ANOVA followed by post hoc test).

The expression of TNF- $\alpha$ in hippocampus was also accessed using immunohistochemistry method (see Supplementary Methods). Compared with sham group, the percentage of TNF- $\alpha$-IR-positive area in the hippocampal CA1 and CA3 was significantly higher in 20 day SNI group (Figure $4 \mathrm{~d}$ and e, $P<0.01$ in CA1 and $P<0.05$ in CA3, $n=6$ in each groups, two-tailed unpaired Student's $t$-test), which is in line with a previous work that TNF- $\alpha$ mRNA is upregulated in hippocampal neurons following peripheral nerve injury (Spengler et al, 2007). These data suggested that increased TNF- $\alpha$ following SNI might be the molecular events underlying the dysfunction of hippocampal synapses and the impairment of memory.
Intracerebroventricular or Intrahippocampal Injection of rrTNF Impairs Both Working Memory and Hippocampal LTP

To test the effect of TNF- $\alpha$ on memory function directly, we investigated whether intracerebroventricular (i.c.v.) injection of $\operatorname{rrTNF}(1 \mu \mathrm{g} / \mathrm{ml}, 5 \mu \mathrm{l}$, in $10 \mathrm{~min}$, see Supplementary Methods) in naive rats is capable of impairing memory function and LTP in hippocampus. In control group the same volume of artificial CSF (aCSF) was injected. At 3 days after cessation of injection, the memory function was evaluated with radial maze. Similar to rats with SNI, the average working memory errors were significantly higher in rrTNF group than those in aCSF group (Figure 5a, $\mathrm{F}_{(1,14)}=22.88, \quad P<0.05, \quad n=8$ in each group, two-way ANOVA), whereas there was no difference in average reference memory errors between the two groups (Figure 5b, $\mathrm{F}_{(1,14)}=5.49, P>0.05$, two-way ANOVA). HFS was able to induce LTP at CA3-CA1 synapses in aCSF group but not in rrTNF group (Supplementary Figure 4a). In 

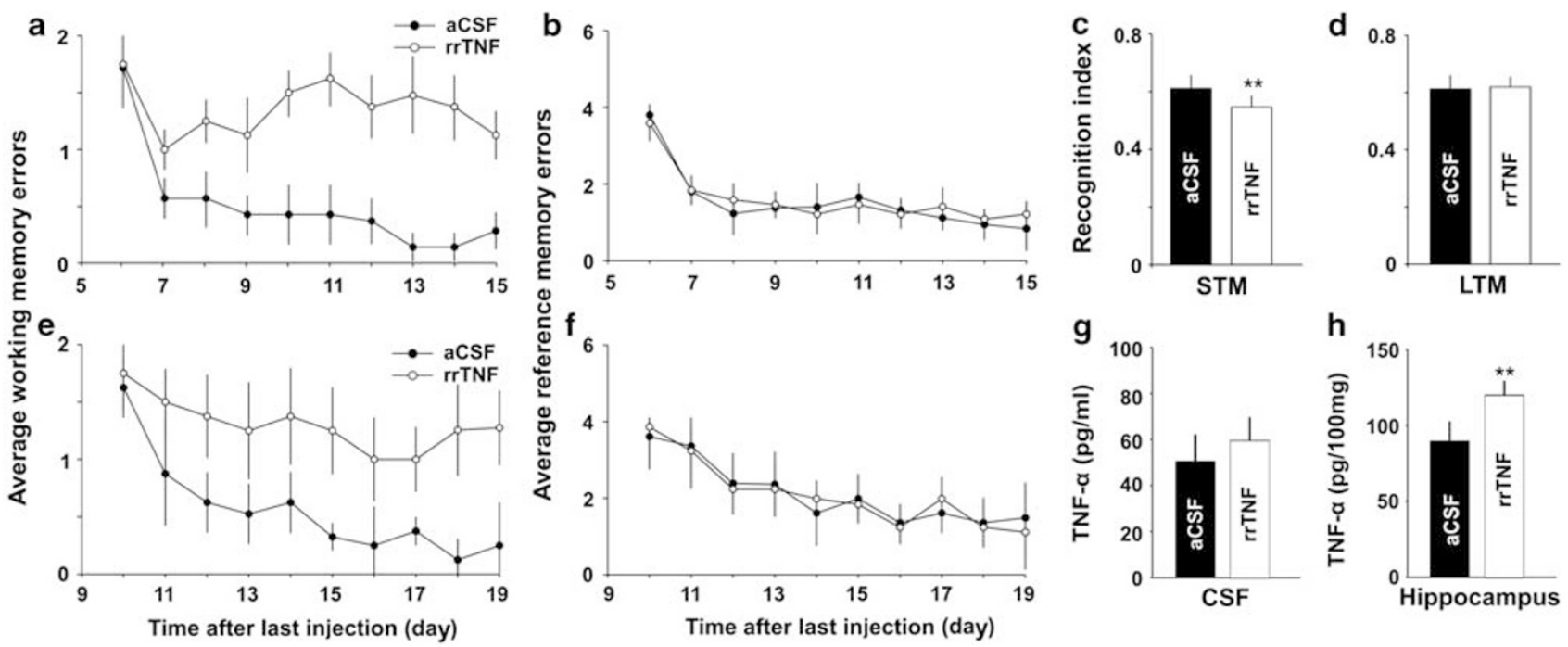

Figure 5 Intracerebroventricular or intrahippocampal injection of rrTNF mimics the effects of SNI. (a and b) Average working memory errors were higher in rats with i.c.v. injection of rrTNF than in aCSF-treated rats, and there was no difference in reference memory performances between the two groups ( $n=8$ in each group). (c-h) The experiments were performed in another cohorts of rats, in which rrTNF $(200 \mathrm{ng} / \mathrm{ml}, 0.5 \mu \mathrm{l})$ or aCSF was infused into bilateral hippocampus for 3 successive days ( $n=8$ in each group). (c and d) The recognition index for short-term memory but not that for long-term memory was lower in rrTNF-treated group than that in aCSF-treated group. (e and f) Average working memory errors were higher in rrTNF-treated group than that in aCSF-treated group, but there was no difference in reference memory performances between two groups. ( $g$ and $h)$ The concentration of TNF- $\alpha$ in hippocampus but not in CSF was higher in rrTNF-treated group, compared with that in aCSF-treated group ( $n=4$ in each group). *** $P<0.0$ I vs aCSF-treated SNI group. Data are presented as means \pm SEM.

addition, i.c.v. injection of $\operatorname{rrTNF}(1 \mu \mathrm{g} / \mathrm{ml}, 5 \mu \mathrm{l}$, in $10 \mathrm{~min})$ in intact rats did not affect baseline of fEPSPs, and identical to the results observed in SNI animals, LTP was blocked at $60 \mathrm{~min}$ after injection (Supplementary Figure $4 \mathrm{~b}$ ). The results indicated that elevation of TNF- $\alpha$ in CSF via exogenous application could imitate the inhibitory effect of SNI on working memory and LTP in hippocampus.

To test whether TNF- $\alpha$ may impair memory by acting in hippocampus but not in other brain regions, $\operatorname{rrTNF}(200 \mathrm{ng} / \mathrm{ml}$, $0.5 \mu$, see Supplementary Methods) or aCSF was injected into bilateral hippocampus for 3 successive days (daily), and 3 days after cessation of injection memory function was accessed with NORT and eight arm maze tests. The index for short-term memory ( $10 \mathrm{~min}$ rotation) in rrTNF-treated group was significantly lower than that in aCSF-treated group (Figure 5c, $P<0.01, n=8$ in each group, two-tailed unpaired Student's $t$-test). There was no difference in the index for long-term memory $(24 \mathrm{~h}$ rotation) between the two groups (Figure 5d, $P>0.05$, two-tailed unpaired Student's $t$-test). In radial eight-arm maze test, the average working memory errors in rrTNF-treated rats were significantly higher, compared with those in aCSF-treated rats (Figure $5 \mathrm{e}, \mathrm{F}_{(1,14)}=26.21, P<0.05, n=8$ in each group, two-way ANOVA), and no difference in reference memory performance between the two groups was detected (Figure 5f, $\mathrm{F}_{(1,14)}=2.16, P>0.05, n=8$ in each group, two-way ANOVA). There was no significant difference in locomotion activity between rrTNF-treated group and aCSF-treated group (Supplementary Figure 1d-e and k). Following the behavioral test, the levels of TNF- $\alpha$ in CSF and hippocampus were measured with ELISA. The concentration of TNF- $\alpha$ in hippocampus (Figure $5 \mathrm{~h}, P<0.01, n=4$ in each group, two-tailed unpaired Student's $t$-test) but not in
CSF (Figure 5g, $P>0.05, n=4$ in each group, two-tailed unpaired Student's $t$-test) was significantly higher in rrTNFtreated group than in aCSF-treated group, suggesting that exogenous rrTNF may stimulate production of endogenous TNF- $\alpha$ in hippocampus.

Intracerebroventricular injection but not intrahippocampal injection of rrTNF produced mechanical allodynia (Supplementary Figure 5).

\section{Intraperitoneal Injection of TNF- $\alpha$ Synthesis Inhibitor or Intracerebroventricular Injection of TNF- $\alpha$ Antibody Prevents the Memory Impairment Produced by SNI}

Having demonstrated that TNF- $\alpha$ increased in CSF and hippocampus following SNI and exogenous application of rrTNF impaired synaptic plasticity and memory function, we next tested whether inhibition of the overproduction of TNF- $\alpha$ was sufficient to prevent the impairment of synaptic plasticity and memory induced by SNI. To do this, thalidomide (a TNF- $\alpha$ synthesis inhibitor), which has no effect on hippocampal LTP but prevents inhibition of LTP mediated by amyloid $\beta$ peptide (Wang et al, 2005), was injected intraperitoneally $(50 \mathrm{mg} / \mathrm{kg})$, starting at $2 \mathrm{~h}$ before SNI and then daily thereafter until day 7 after surgery. Similar to our previous work (Xu et al, 2006), injection of thalidomide prevented mechanical allodynia produced by SNI (Figure 6a, $P<0.05$ compared with DMSO-treated group, $n=8-10$ in each group, Mann-Whitney $U$-test). There was no difference in paw withdrawal thresholds between thalidomide-treated SNI rats and sham rats (Figure 6a, $P>0.05$, Mann-Whitney $U$-test). Importantly, we found that the average working memory errors in thalidomide-treated group were significantly lower than 

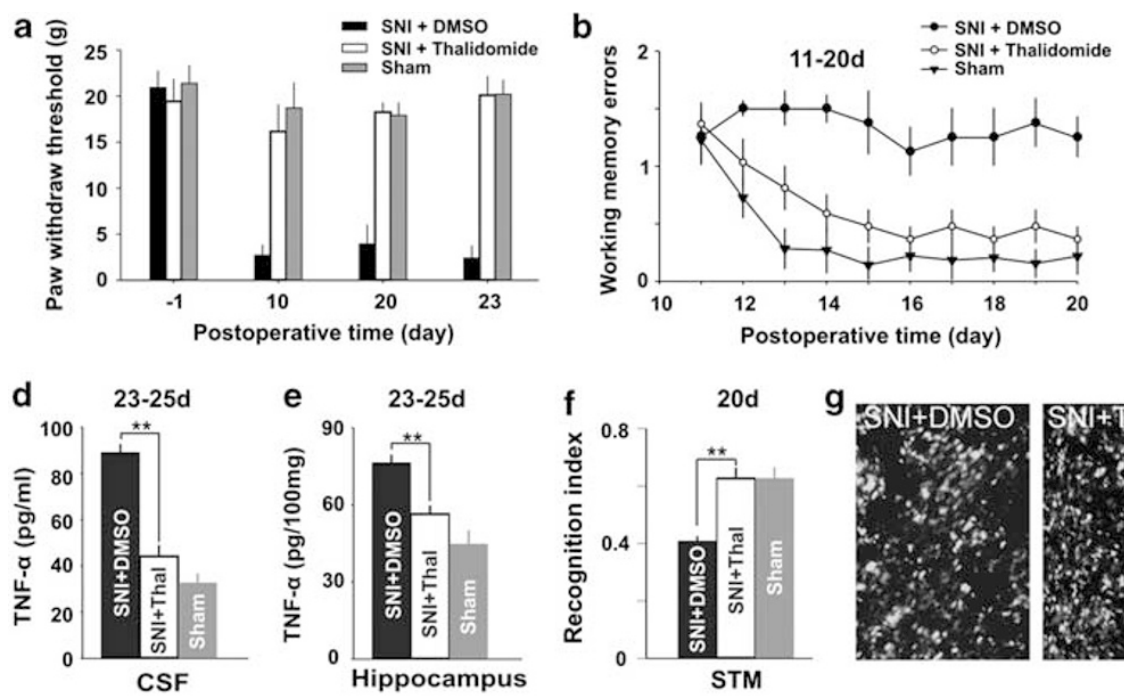
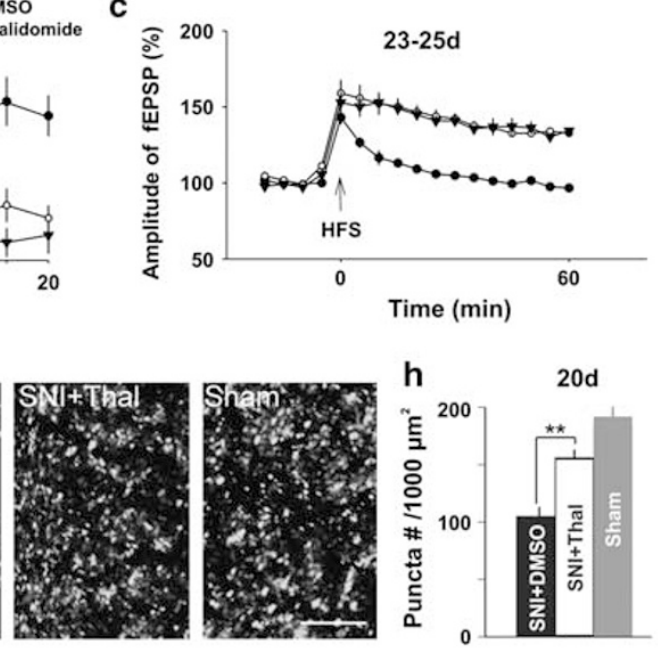

Figure 6 Inhibition of TNF- $\alpha$ synthesis by thalidomide prevents memory deficits and synaptic dysfunction produced by SNI. (a) Paw withdrawal thresholds decreased in DMSO-treated SNI group but not in thalidomide-treated SNI group and sham group ( $n=8-10$ in each group). (b) Average working memory errors in the thalidomide-treated SNI rats were lower than those in DMSO-treated SNI rats, and were not different from those in sham rats. (c) HFS induced LTP in thalidomide-treated SNI rats and sham rats but not in DMSO-treated SNI rats. ( $d$ and e) The concentration of TNF- $\alpha$ in three groups of rats as indicated are shown. ( $f$ ) The recognition index for short-term memory was significantly higher in thalidomide-treated SNI rats than that in DMSO-treated $\mathrm{SNI}$ rats. There is no difference between sham rats and thalidomide-treated SNI rats ( $n=8$ in each group). ( $g$ and $h)$ The density of presynaptic terminal puncta was higher in thalidomide-treated SNI group than that in DMSO-treated SNI group ( $n=8$ in each group). Scale bar $=10 \mu \mathrm{m}$. *** $P<0.0 \mathrm{I}$ compared with DMSO-treated SNI group. Data are presented as means \pm SEM.

those in DMSO-treated group (Figure 6b, $\mathrm{F}_{(1,14)}=24.46$, $P<0.05$, two-way ANOVA), but were not different from those in sham group (Figure $6 \mathrm{~b}, \mathrm{~F}_{(1,16)}=1.97, P>0.05$, twoway ANOVA). Furthermore, LTP at CA3-CA1 synapses in the SNI rats treated with thalidomide was not different from that in sham-operated rats, whereas in SNI rats treated with DMSO HFS failed to induce LTP (Figure 6c). The results indicated that the impairment of working memory and LTP by SNI was completely prevented by the pretreatment with thalidomide. To verify the increase in TNF- $\alpha$ was really prevented by thalidomide, CSF and hippocampal tissue were harvested following LTP recordings for assessment of TNF- $\alpha$. The concentrations of the cytokine in both CSF and hippocampal tissue were significantly lower in thalidomidetreated SNI group than in vehicle-treated SNI group (Figure $6 \mathrm{~d}$ and $\mathrm{e}, \mathrm{F}_{(2,23)}=146.28$ in $\mathrm{CSF}$ and $\mathrm{F}_{(2,23)}=20.71$ in hippocampal tissue, $P<0.01$, one-way ANOVA followed by post hoc test), and there was no difference between thalidomide-treated group and sham group (Figure 6d and e, $P>0.05$, one-way ANOVA followed by post hoc test).

In another set of experiments, we found that in SNI rats the recognition index for short-term memory detected by NORT was significantly lower in DMSO group than that in thalidomide group (Figure 6f, $P<0.01, n=8$ in each group, two-tailed unpaired student's $t$-test), and the index in the SNI rats treated with thalidomide was not different from that in sham group (Figure 6f, $P>0.05$, two-tailed unpaired student's $t$-test). There was no significant difference in locomotion activity among three groups in the two behavioral tests (Supplementary Figure if and l). Furthermore, the density of presynaptic boutons in CA1 was also significantly lower in DMSO-treated SNI group than those in thalidomide-treated SNI group (Figure $6 \mathrm{~g}$ and $\mathrm{h}, P<0.01$, two-tailed unpaired student's $t$-test), and there was no difference between sham rats and thalidomide-treated SNI rats (Figure $6 \mathrm{~g}$ and $\mathrm{h}, P>0.05$, two-tailed unpaired student's $t$-test). The results suggested that the inhibition of overproduction of TNF- $\alpha$ might be sufficient to prevent the structural and functional impairment produced by SNI.

As the inhibitory effect of thalidomide on TNF- $\alpha$ synthesis may be not specific, to confirm the effect of increased TNF- $\alpha$ on memory function, TNF- $\alpha$ antibody $(250 \mu \mathrm{g} / \mathrm{ml}, 5 \mu \mathrm{l}$, see Supplementary Methods) or aCSF was injected into cerebral ventricle at $2 \mathrm{~h}$ before and after SNI for 7 days (daily), and then memory function was evaluated with NORT and eight-arm maze tests. The recognition index for short-term memory (10 min rotation) was significantly higher in anti-TNF- $\alpha$-treated group than that in aCSFtreated group (Figure $7 \mathrm{a}, P<0.01, n=7$ in each group, twotailed unpaired Student's $t$-test), but no difference in the index for long-term memory ( $24 \mathrm{~h}$ rotation) was detected between the two groups (Figure $7 \mathrm{~b}, P>0.05$, two-tailed unpaired Student's $t$-test). Average working memory errors were significantly lower in anti-TNF- $\alpha$-treated group, compared with aCSF-treated group (Figure 7c, $\mathrm{F}_{(1,12)}=22.38, \quad P<0.05, \quad n=7$ in each group, two-way ANOVA) and there was no difference in average reference memory errors between the two groups (Figure $7 \mathrm{~d}$, $\mathrm{F}_{(1,12)}=1.09, P>0.05$, two-way ANOVA). There was no significant difference in locomotion activity between antiTNF- $\alpha$-treated SNI group and aCSF-treated SNI group (Supplementary Figure $1 \mathrm{~g}$ and $\mathrm{m}$ ). The levels of TNF- $\alpha$ in both CSF and in hippocampus were significantly lower in anti-TNF- $\alpha$-treated rats, compared with that in aCSF-treated rats (Figure $7 \mathrm{e}$ and $\mathrm{f}, P<0.01, n=4$ in each group, twotailed unpaired Student's $t$-test). 

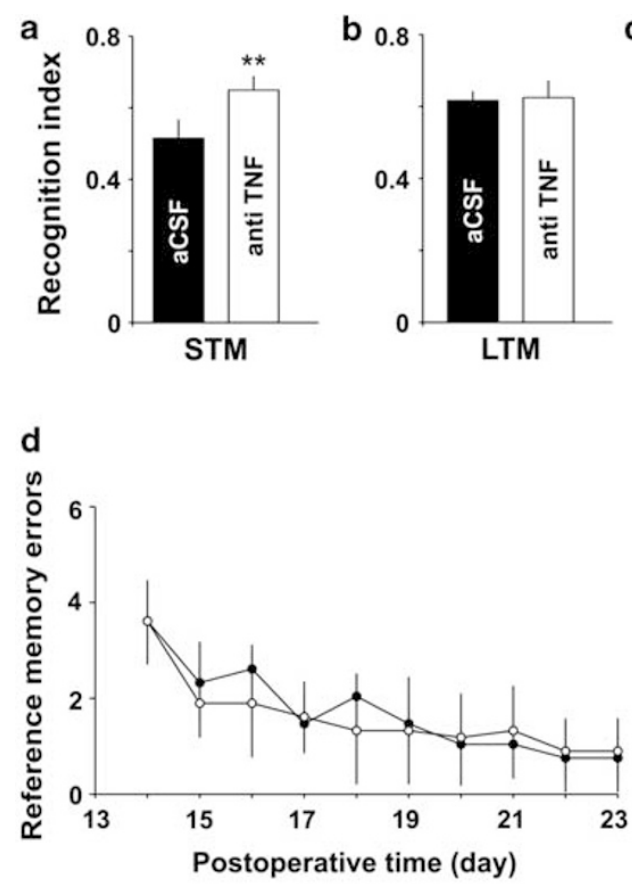

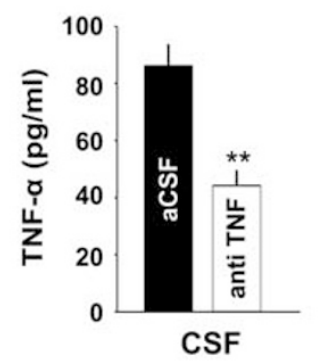

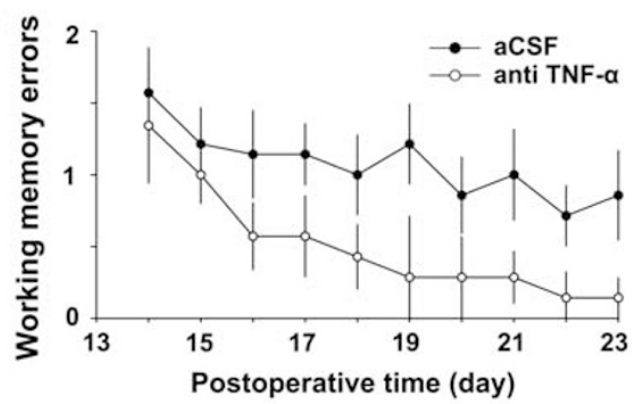

f

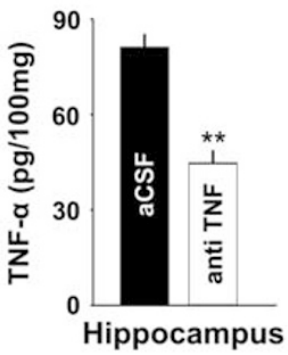

Figure 7 Intracerebroventricular injection of TNF- $\alpha$ antibody attenuates memory impairment induced by SNI. (a and b) The recognition index for shortterm memory but not that for long-term memory tested at I 0 days and at II days after SNI was significantly higher in anti-TNF- $\alpha$-treated group than that in aCSF-treated group ( $n=7$ in each group). (c and d) Average working memory errors but not average reference memory errors accessed after SNI were significantly lower in anti-TNF- $\alpha$-treated group, compared with aCSF-treated group ( $n=7$ in each group). (e and $f$ ) The concentrations of TNF- $\alpha$ in both CSF and in hippocampus were significantly lower in anti-TNF- $\alpha$-treated rats, compared with aCSF-treated rats $(n=4$ in each group). $* * P<0.0$ I vs aCSF-treated group. Data are presented as means \pm SEM.

The Effects of SNI on Memory Performance and Hippocampal Synaptic Plasticity in Wide-Type Mice and TNFR1 KO Mice

To determine which subtype of TNF receptors is involved in memory deficits, we performed the experiments with TNFR1 KO and wild-type (WT) mice at 20 days after SNI. In WT mice, we found again that the average working memory errors in SNI group was significantly higher than those in sham group (Figure $8 \mathrm{a}, \mathrm{F}_{(1,14)}=20.32, P<0.05$, $n=8$ in each group, two-way ANOVA). In contrast, in TNFR1 KO mice there was no difference in working memory errors between sham and SNI group (Figure 8f, $\mathrm{F}_{(1,14)}=34.24, \quad P>0.05, \quad n=8$ in each group, two-way ANOVA). The potentiation by HFS persisted for at least $2 \mathrm{~h}$ (up to $5 \mathrm{~h}$ ) in sham KO and sham WT mice, but for only $1 \mathrm{~h}$ in SNI KO mice and for $15 \mathrm{~min}$ in SNI WT mice (Figure $8 \mathrm{~b}$ and $\mathrm{g}$ ). The results indicated that in TNFR1 KO mice SNI did not affect working memory, but impaired late-phase LTP.

To further evaluate the role of TNFR 1 in memory deficits in SNI mice, we investigated the effects of SNI on short-term memory measured with NORT, and the density of presynaptic boutons in WT and TNFR1 KO mice at 20 days after SNI and sham operation. The results showed that SNI impaired the short-term memory in WT mice but not in TNFR1 KO mice, as in WT mice the recognition index for short-term memory was significantly lower in SNI group than that in sham group (Figure $8 c, P<0.01, n=8$ in each group, two-tailed unpaired student's $t$-test), whereas in TNFR1 KO mice there was no difference between SNI group and sham group (Figure $8 \mathrm{~h}, P>0.05, n=8$ in each group, two-tailed unpaired student's $t$-test). In addition, the cognition index was lower in sham-operated TNFR1 KO mice than that in sham-operated WT mice (Figure $8 \mathrm{c}$ and $\mathrm{h}$, $1.38 \pm 0.21$ vs $1.59 \pm 0.15, \quad P<0.05$, two-tailed unpaired student's $t$-test). The locomotion activity in TNFR1 KO mice is not different from that in WT mice (Supplementary Figure $1 \mathrm{~h}-\mathrm{i}$ and $\mathrm{n}-\mathrm{o}$ ). Together, the deletion of TNFR1 might reduce short-term memory slightly but prevent the memory deficits produced by SNI. In WT mice the density of presynaptic boutons was significantly lower in SNI mice, compared with that in sham-operated mice (Figure 8d and e, $P<0.01$, two-tailed unpaired student's $t$-test), whereas in TNFR1 KO mice there was no difference between SNI and sham groups (Figure $8 \mathrm{i}$ and $\mathrm{j}, P>0.05$, two-tailed unpaired student's $t$-test). The results suggested that SNI reduced synaptic connections in WT mice, but not in TNFR1 KO mice. Consistent with the morphological finding, in TNFR1 KO mice the frequency facilitation induced by 2,4 , and $8 \mathrm{~Hz}$ in SNI group was not different from that in sham group (Figure 9a-d, $P>0.05, n=5$ in each group, two-way ANOVA). Thus, the increased TNF- $\alpha$ might exert the detrimental effect on memory function mainly by activation of TNFR1.

\section{DISCUSSION}

In this work, we showed that SNI impaired the spatial working memory or short-term memory in rats and in mice. 

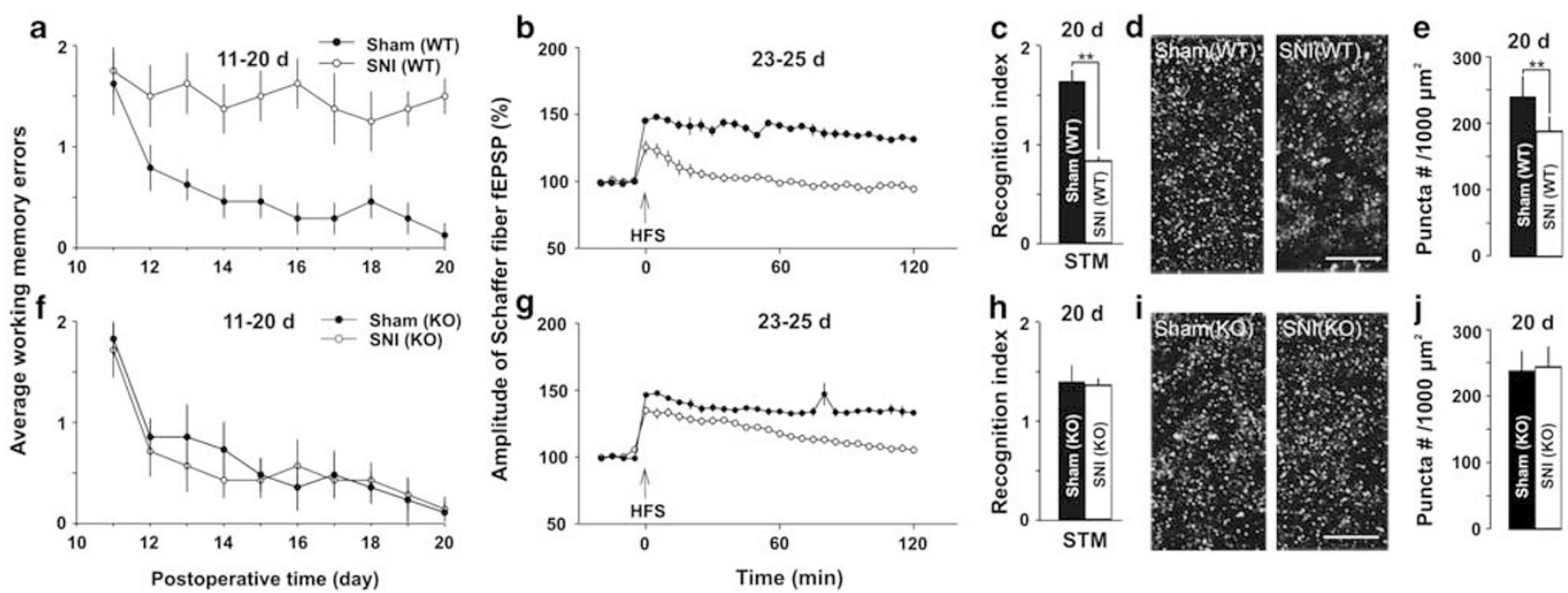

Figure 8 The differential effects of SNI on memory function and hippocampal synapses in wild-type (WT) and TNFRI-knockout mice. (a and b) In WT mice, working memory performance and LTP at CA3-CAI synapses were impaired in SNI but not in sham-operation group ( $n=8$ in each group). (c-e) The short-term memory index evaluated by NORT and presynaptic synaptophysin puncta density in CAI are significant lower in SNI WT mice than those in Sham WT mice ( $n=8$ in each group). ( $f$ There was no difference between SNI KO mice and Sham KO mice in working memory performance. (g) The time course of potentiation induced by HFS in SNI KO mice and Sham KO mice, as indicated, at 23-25 days after operation ( $n=8$ in each group). (h) Recognition index for short-term memory in SNI KO and sham KO mice are shown ( $n=8$ in each group). ( $i$ and j) The representative images show the presynaptic synaptophysin puncta in CAI from KO mice after operation and the summary data of presynaptic terminal puncta densities in KO mice. Scale bar $=10 \mu \mathrm{m} . * * P<0.01$ compared with sham group and data are presented as means \pm SEM.

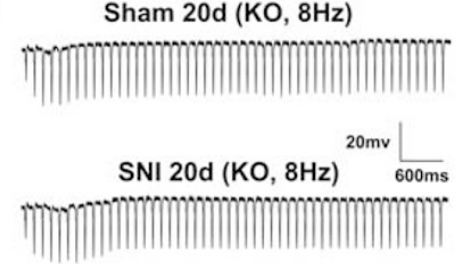

$1-50$ stimuli

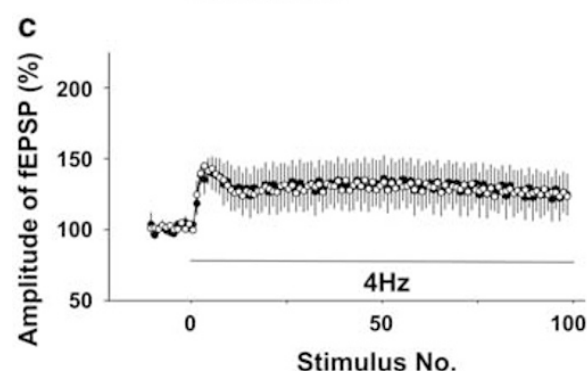

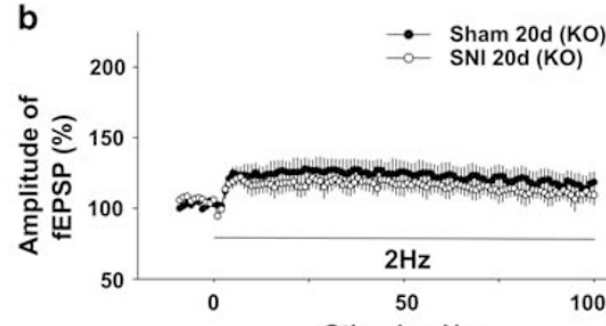

Stimulus No.

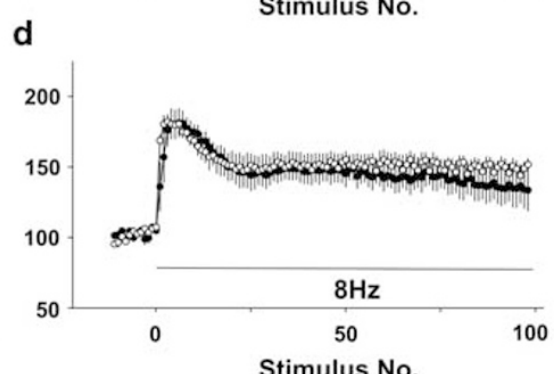

Figure 9 SNI does not affect the frequency facilitation in TNFRI knockout mice. (a) The raw traces of fEPSPs evoked by $8 \mathrm{~Hz}$ stimuli ( I-50 pulses) in SNI and sham-operated TNFRI KO mice. (b-d) There was no difference in frequency facilitation produced by 2,4 , and $8 \mathrm{~Hz}$ stimuli between $\mathrm{SNI}$ and sham groups in TNFRI-knockout mice ( $n=5$ in each group). Data are presented as means \pm SEM.

These data are consistent with the recent reports that spatial memory is reduced in SNI (Leite-Almeida et al, 2009) or spinal nerve ligation ( $\mathrm{Hu}$ et al, 2010) models of neuropathic pain. These experimental data are in line with clinical studies that around two-third of chronic pain patients have working memory impairment (Dick and Rashiq, 2007). Importantly, we demonstrated for the first time that the memory impairment produced by peripheral nerve injury was associated with dysfunction of the hippocampus, ie, the disruption of LTP and frequency facilitation at CA3-CA1 synapses, as well as the reduction of presynaptic boutons in hippocampal CA1 region. At the molecular level, peripheral nerve injury increased TNF- $\alpha$ in CSF, in hippocampus and in plasma. The increase in TNF- $\alpha$ was temporally correlated with the impairment of synaptic plasticity and memory. Intracerebroventricular or intrahippocampal injection of rrTNF mimicked the effects of SNI, whereas inhibition of TNF- $\alpha$ or genetic deletion of TNFR1 prevented both memory deficits and synaptic dysfunction produced by SNI. Our results suggested that peripheral nerve injury 
might lead to memory deficits by impairing structure and function of hippocampus via upregulation of TNF- $\alpha$.

\section{Functional and Structural Damage of Hippocampus may Contribute to the Memory Deficits Following Peripheral Nerve Injury}

As mentioned in Introduction, it has been proposed (Eccleston, 1995) that pain may lead to working memory deficits by competing limited attention resources. The model is further extended recently (Legrain et al, 2009). However, the hypothesis is contradictory to the clinical findings that acute pain in health individuals does not produce cognitive deficit (Etherton et al, 2006), and that the relief of pain with opioids in chronic pain patients is incapable of improving cognitive function (Dick and Rashiq, 2007). In harmony with the clinical findings, the present work showed that the impairment of memory and hippocampal LTP was evident not only in animals with mechanical allodynia but also in a small part of animals that did not exhibit the behavioral sign of neuropathic pain following SNI. Moreover, SNI (cutting the common peroneal and the tibial nerves), which may activate the majority (if not all) of nociceptive afferents, had no acute effect on basal synaptic transmission and LTP induction in hippocampus, suggesting that nociceptive inputs (pain signals) may not affect synaptic transmission and plasticity directly. Importantly, peripheral nerve injury induced a delayed LTP impairment in bilateral hippocampus. As short-term potentiation $(<30 \mathrm{~min})$ could still be recorded in the SNI rats, the failure of LTP induction may not be due to the saturation of synaptic potentiation, but due to the impairment of synaptic plasticity. In addition, we found that the presynaptic terminal puncta density was reduced and the frequency facilitation was inhibited following SNI. Altogether, our data suggested that the memory deficits produced by peripheral nerve injury might be not resulted from nociceptive inputs but from dysfunction of synaptic connection in hippocampus.

\section{The Increased TNF- $\alpha$ may Contribute to Both Neuropathic Pain and the Memory Deficits Following Peripheral Nerve Injury}

In contrast to the theory by Eccleston (1995), Hart et al (2000) have proposed that the unknown molecules that disrupt neural circuitries underlying attention and memory may cause the cognitive deficits in chronic pain patients. We suggest that TNF- $\alpha$ may be one of these molecules, which may impair memory and induce neuropathic pain after peripheral nerve injury.

TNF- $\alpha$ can be synthesized and released in the brain by glial cells and neurons, and exerts multifunctions by binding to two different TNF receptors (p55 or TNFR1 and p75 or TNFR2), which are constitutively expressed in nervous system (Pickering et al, 2005). Previous studies have revealed that TNF- $\alpha$ is upregulated in nervous system following peripheral nerve injury and the increased TNF- $\alpha$ is critical for the development of chronic neuropathic pain (Ignatowski et al, 1999; Sekiguchi et al, 2009; Xu et al, 2006). Interestingly, in hippocampus, pathological concentration of TNF- $\alpha$ inhibits LTP (Butler et al, 2004; Cunningham et al,
1996; Pickering and O'Connor, 2007; Tancredi et al, 1992). In this study, we found that TNF- $\alpha$ increased in CSF, in hippocampus, and in plasma after peripheral nerve injury, which was closely correlated with LTP inhibition. Both of the changes were detected at $18 \mathrm{~h}$ but not at $1 \mathrm{~h}$ after SNI. Intracerebroventricular or intrahippocampal injection of rrTNF mimicked the memory deficits and impairment in the function of CA1 synapses produced by peripheral nerve injury, whereas inhibition of TNF- $\alpha$ or genetic deletion of TNFR1 prevented the effects of SNI. These results suggest that the overproduction of TNF- $\alpha$ may be responsible for dysfunction of hippocampus. As TNF- $\alpha$ increased in CSF and in blood following SNI, it is not surprising that the LTP was inhibited in bilateral hippocampus. The delayed and bilateral inhibition of hippocampal LTP induced by increase in TNF- $\alpha$ might contribute to memory deficits. However, we also found that genetic deletion of TNFR1 could not completely prevent the inhibitory effect of SNI on LTP, as in TNFR1 KO mice the potentiation induced by HFS lasted for $<1 \mathrm{~h}$ in SNI group, which was shorter than that in sham group (for up to $5 \mathrm{~h}$ ). Therefore, apart from TNF- $\alpha$, other factors may be also involved in inhibition of hippocampal LTP following peripheral nerve injury.

How could peripheral nerve injury increase TNF- $\alpha$ in the hippocampus? As peripheral nerve injury upregulates TNF- $\alpha$ within $3 \mathrm{~h}$ in DRG (Rothman et al, 2009) and in the present study only peripheral nerve (axons of DRG neurons and motor neurons) was injured, we speculated that TNF- $\alpha$ might increase in DRG at first. Previously, we have shown that TNF- $\alpha$ promotes itself production via activation of nucleus factor- $\kappa \mathrm{B}$ in DRG and in spinal dorsal horn (Wei et al, 2007). It is possible that TNF- $\alpha$ released from DRG and spinal dorsal horn might diffuse into CSF and trigger the production of TNF- $\alpha$ in other brain regions, including hippocampus, by the same autocrine mechanism. Alternatively, peripheral nerve injury may increase the permeability of blood brain barrier, allowing hematogenous macrophages and $\mathrm{CD}^{+}{ }^{+} \mathrm{T}$ cells to invade the central nervous system (Cao et al, 2009; Cao and DeLeo, 2008; Zhang et al, 2007). Both the autocrine of TNF- $\alpha$ and the infiltration of immunocytes may contribute to the persistent increase in TNF- $\alpha$ in hippocampus. Further study is needed to elucidate this issue.

Clinically, the memory impairment was intensively studied in the patients with fibromyalgia and low back pain (Hart et al, 2000). As fibromyalgia and neuropathic pain display similar clinical features (see Offenbaecher and Ackenheil, 2005 for a review) and share overlapping pathophysiological processes, it has been proposed that the two diseases may be variations of the same condition (see Maletic and Raison, 2009 for a review). The central mechanisms of low back pain are also similar to those of neuropathic pain (Audette et al, 2005). Importantly, it has been shown that serum concentration of TNF- $\alpha$ is increased in the patients with both fibromyalgia and low back pain, and is reduced following multidisciplinary treatment of pain (Wang et al, 2008a, b). Therefore, this data obtained in animal model of chronic neuropathic pain may explain the memory deficits in the patients with some forms of chronic pain.

In summary, following peripheral nerve injury the increased TNF- $\alpha$ may not only contribute to the chronic 
pain, but also to memory deficits by dysfunction of hippocampus. Therefore, the drugs targeting to TNF- $\alpha$ and its downstream molecules may treat both of the disorders.

\section{ACKNOWLEDGEMENTS}

We thank William D Willis Jr for editing the English of the manuscript. This work was supported by grants from the National Natural Science Foundation of China (no: 30770705) to XGL and (30630026) to GL, the Ministry of education of China (20060558001) to XGL, and National Basic Research Program of China (2009CB941303) to GL.

\section{DISCLOSURE}

The authors declare no conflict of interest.

\section{REFERENCES}

Alloway TP, Gathercole SE, Kirkwood H, Elliott J (2009). The cognitive and behavioral characteristics of children with low working memory. Child Dev 80: 606-621.

Audette JF, Emenike E, Meleger AL (2005). Neuropathic low back pain. Curr Pain Headache Rep 9: 168-177.

Awh E, Vogel EK, Oh SH (2006). Interactions between attention and working memory. Neuroscience 139: 201-208.

Bruel-Jungerman E, Davis S, Laroche S (2007). Brain plasticity mechanisms and memory: a party of four. Neuroscientist 13: 492-505.

Butler MP, O’Connor JJ, Moynagh PN (2004). Dissection of tumornecrosis factor-alpha inhibition of long-term potentiation (LTP) reveals a p38 mitogen-activated protein kinase-dependent mechanism which maps to early-but not late-phase LTP. Neuroscience 124: 319-326.

Cao L, DeLeo JA (2008). CNS-infiltrating CD4+ T lymphocytes contribute to murine spinal nerve transection-induced neuropathic pain. Eur J Immunol 38: 448-458.

Cao L, Palmer CD, Malon JT, De Leo JA (2009). Critical role of microglial CD40 in the maintenance of mechanical hypersensitivity in a murine model of neuropathic pain. Eur J Immunol 39: 3562-3569.

Chaplan SR, Bach FW, Pogrel JW, Chung JM, Yaksh TL (1994). Quantitative assessment of tactile allodynia in the rat paw. J Neurosci Methods 53: 55-63.

Cunningham AJ, Murray CA, O’Neill LA, Lynch MA, O'Connor JJ (1996). Interleukin-1 beta (IL-1 beta) and tumour necrosis factor (TNF) inhibit long-term potentiation in the rat dentate gyrus in vitro. Neurosci Lett 203: 17-20.

Decosterd I, Woolf CJ (2000). Spared nerve injury: an animal model of persistent peripheral neuropathic pain. Pain 87: 149-158.

Dick BD, Rashiq S (2007). Disruption of attention and working memory traces in individuals with chronic pain. Anesth Analg 104: 1223-1229.

Eccleston C (1995). Chronic pain and distraction: an experimental investigation into the role of sustained and shifting attention in the processing of chronic persistent pain. Behav Res Therapy 33: 391-405.

Etherton JL, Bianchini KJ, Ciota MA, Heinly MT, Greve KW (2006). Pain, malingering and the WAIS-III working memory index. Spine J 6: 61-71.

George A, Buehl A, Sommer C (2004). Wallerian degeneration after crush injury of rat sciatic nerve increases endo- and epineurial tumor necrosis factor-alpha protein. Neurosci Lett 372: 215-219.
George A, Marziniak M, Schafers M, Toyka KV, Sommer C (2000). Thalidomide treatment in chronic constrictive neuropathy decreases endoneurial tumor necrosis factor-alpha, increases interleukin-10 and has long-term effects on spinal cord dorsal horn met-enkephalin. Pain 88: 267-275.

Gould E, Leuner B (2010). Structural plasticity and hippocampal function. Annu Rev Psychol 67: 111-140.

Hart RP, Martelli MF, Zasler ND (2000). Chronic pain and neuropsychological functioning. Neuropsychol Rev 10: 131-149.

Hu Y, Yang J, Hu Y, Wang Y, Li W (2010). Amitriptyline rather than lornoxicam ameliorates neuropathic pain-induced deficits in abilities of spatial learning and memory. Eur J Anaesthesiol 27: $162-168$.

Ignatowski TA, Covey WC, Knight PR, Severin CM, Nickola TJ, Spengler RN (1999). Brain-derived TNFalpha mediates neuropathic pain. Brain Res 841: 70-77.

International Association for the Study of Pain (1986). Classification of chronic pain. Descriptions of chronic pain syndromes and definitions of pain terms. Pain 3: 1-225.

Kesner RP (2007). Behavioral functions of the CA3 subregion of the hippocampus. Learn Mem 14: 771-781.

Legrain V, Damme SV, Eccleston C, Davis KD, Seminowicz DA, Crombez G (2009). A neurocognitive model of attention to pain: behavioral and neuroimaging evidence. Pain 144: 230-232.

Leite-Almeida H, Almeida-Torres L, Mesquita AR, Pertovaara A, Sousa N, Cerqueira JJ et al (2009). The impact of age on emotional and cognitive behaviours triggered by experimental neuropathy in rats. Pain 144: 57-65.

Leuner B, Shors TJ (2004). New spines, new memories. Mol Neurobiol 29: 117-130.

Leung LW (1979). Orthodromic activation of hippocampal CA1 region of the rat. Brain Res 176: 49-63.

Maletic V, Raison CL (2009). Neurobiology of depression, fibromyalgia and neuropathic pain. Front Biosci 14: 5291-5338.

Noguchi K, Obata K, Dai Y (2004). Changes in DRG neurons and spinal excitability in neuropathy. Novartis Found Symp 261: $103-110$

Offenbaecher M, Ackenheil M (2005). Current trends in neuropathic pain treatments with special reference to fibromyalgia. CNS Spectr 10: 285-297.

Pickering M, Cumiskey D, O'Connor JJ (2005). Actions of TNFalpha on glutamatergic synaptic transmission in the central nervous system. Exp Physiol 90: 663-670.

Pickering M, O'Connor JJ (2007). Pro-inflammatory cytokines and their effects in the dentate gyrus. Prog Brain Res 163: 339-354.

Ribeiro RA, Vale ML, Ferreira SH, Cunha FQ (2000). Analgesic effect of thalidomide on inflammatory pain. Eur J Pharmacol 391: 97-103.

Rothman SM, Huang Z, Lee KE, Weisshaar CL, Winkelstein BA (2009). Cytokine mRNA expression in painful radiculopathy. J Pain 10: 90-99.

Schafers M, Brinkhoff J, Neukirchen S, Marziniak M, Sommer C (2001). Combined epineurial therapy with neutralizing antibodies to tumor necrosis factor-alpha and interleukin-1 receptor has an additive effect in reducing neuropathic pain in mice. Neurosci Lett 310: 113-116.

Sekiguchi M, Sekiguchi Y, Konno SI, Kobayashi H, Homma Y, Kikuchi SI (2009). Comparison of neuropathic pain and neuronal apoptosis following nerve root or spinal nerve compression. Eur Spine J 18: 1978-1985.

Shamash S, Reichert F, Rotshenker S (2002). The cytokine network of Wallerian degeneration: tumor necrosis factor-alpha, interleukin-1alpha, and interleukin-1beta. J Neurosci 22: 3052-3060.

Sommer C, Lindenlaub T, Teuteberg P, Schafers M, Hartung T, Toyka KV (2001). Anti-TNF-neutralizing antibodies reduce 
pain-related behavior in two different mouse models of painful mononeuropathy. Brain Res 913: 86-89.

Spengler RN, Sud R, Knight PR, Ignatowski TA (2007). Antinociception mediated by alpha(2)-adrenergic activation involves increasing tumor necrosis factor alpha (TNFalpha) expression and restoring TNFalpha and alpha(2)-adrenergic inhibition of norepinephrine release. Neuropharmacology 52: 576-589.

Sun HY, Lyons SA, Dobrunz LE (2005). Mechanisms of target-cell specific short-term plasticity at Schaffer collateral synapses onto interneurones $v s$ pyramidal cells in juvenile rats. J Physiol 568: 815-840.

Tancredi V, D’Arcangelo G, Grassi F, Tarroni P, Palmieri G, Santoni A et al (1992). Tumor necrosis factor alters synaptic transmission in rat hippocampal slices. Neurosci Lett 146: 176-178.

Tobinick E (2009). Perispinal etanercept for neuroinflammatory disorders. Drug Discov Today 14: 168-177.

Toth C, Lander J, Wiebe S (2009). The prevalence and impact of chronic pain with neuropathic pain symptoms in the general population. Pain Med 10: 918-929.

Vago DR, Kesner RP (2008). Disruption of the direct perforant path input to the CA1 subregion of the dorsal hippocampus interferes with spatial working memory and novelty detection. Behav Brain Res 189: 273-283.

Wang H, Moser M, Schiltenwolf M, Buchner M (2008a). Circulating cytokine levels compared to pain in patients with fibromyalgia - a prospective longitudinal study over 6 months. J Rheumatol 35: 1366-1370.
Wang H, Schiltenwolf M, Buchner M (2008b). The role of TNFalpha in patients with chronic low back pain-a prospective comparative longitudinal study. Clin J Pain 24: 273-278.

Wang Q, Wu J, Rowan MJ, Anwyl R (2005). Beta-amyloid inhibition of long-term potentiation is mediated via tumor necrosis factor. Eur J Neurosci 22: 2827-2832.

Wei XH, Zang Y, Wu CY, Xu JT, Xin WJ, Liu XG (2007). Perisciatic administration of recombinant rat TNF-alpha induces mechanical allodynia via upregulation of TNF-alpha in dorsal root ganglia and in spinal dorsal horn: the role of NF-kappa B pathway. Exp Neurol 205: 471-484.

Xu JT, Xin WJ, Zang Y, Wu CY, Liu XG (2006). The role of tumor necrosis factor-alpha in the neuropathic pain induced by lumbar 5 ventral root transection in rat. Pain 123: 306-321.

Xu L, Anwyl R, Rowan MJ (1997). Behavioural stress facilitates the induction of long-term depression in the hippocampus. Nature 387: 497-500.

Yamanaka H, Obata K, Fukuoka T, Dai Y, Kobayashi K, Tokunaga A et al (2004). Tissue plasminogen activator in primary afferents induces dorsal horn excitability and pain response after peripheral nerve injury. Eur J Neurosci 19: 93-102.

Zhang J, Shi XQ, Echeverry S, Mogil JS, De Koninck Y, Rivest S (2007). Expression of CCR2 in both resident and bone marrowderived microglia plays a critical role in neuropathic pain. J Neurosci 27: 12396-12406.

Zou LB, Yamada K, Tanaka T, Kameyama T, Nabeshima T (1998). Nitric oxide synthase inhibitors impair reference memory formation in a radial arm maze task in rats. Neuropharmacology 37: 323-330.

Supplementary Information accompanies the paper on the Neuropsychopharmacology website (http://www.nature.com/npp) 